\title{
The Department of State and the Acquisition of Research Materials of Foreign Origin
}

THE government of the United States is I a heavy consumer of foreign publications in all categories. For many years it has made use of certain techniques in their procurement familiar enough to nongovernmental institutions whose research likewise depends in greater or less measure upon such materials. It has had at its disposal in addition, however, at least one other avenue of access to the literature of the world not available to the private research institutions-the foreign service.

With the experience of World War II now behind it, this government has been forced to the conclusion that its former procurement techniques were inadequate. This inadequacy was amply demonstrated by the dearth of vital foreign research materials at Washington's disposal at the outset of the war. Moreover, during the period of hostilities, not only the normal commercial channels, but also the exchanges were in a chaotic state. The burden of federal procurement throughout the war, therefore, was placed upon two principal sources of supply - the foreign service and an interdepartmental committee created for the express purpose of acquiring foreign publications. Between them, these sources secured thousands of foreign titles ranging from the daily press and vital periodical literature to maps, charts, statistical yearbooks, and other materials necessary to the conduct of the public business in wartime.

Hostilities having terminated, the prob- lem has become that of reassessing former methods, analysing future demands, and attempting to relate the two with a view to making such changes, additions, or other alterations in procurement techniques as appear to be necessary to satisfy the greatly enlarged demand for foreign research materials.

By far the greatest proportion of foreign material procured for the government prior to the war was secured through one or the combination of two channels: (I) commercial, supplemented by traveling agents of individual agencies, and (2) exchange. In addition to the fact that, pragmatically judged, these sources produced considerably less than the desired quantity of publications, the methods in themselves were not entirely satisfactory. The reasons for this will be apparent to any librarian responsible for substantial foreign acquisitions.

Exchanges, as between government and government, stem from the Brussels Conventions of 1886 . In terms of the needs of this government their principal weaknesses have been that (I) they provided for the exchange of only single copies of the specified classes of official publications; (2) they did not cover provincial, municipal, professional, or other important private publications; (3) they did not provide for the establishment of new exchanges; (4) they did not of themselves provide the means for fluid ad justment to changes in departments and ministries; and (5) they did not con- 
stitute suitable sources of bibliographical data. As a result, the various departments and agencies of this government adopted the method of establishing direct exchange relationships with their counterpart or nearcounterpart agencies in specific foreign countries. In many ways this affected the needed relationships, but it remained essentially outside of the formal governmentto-government pattern and gave rise to numerous additional administrative problems of integration as well as to an enormous amount of additional labor on the part of the separate agencies.

On the other hand, direct purchase through normal commercial channels also proved less than efficient as a method of procurement. In general, it may be said that the two chief drawbacks have been ( I) the lack of adequate bibliographical information upon which to base sound purchase procedures and (2) a time lag, usually extending over a period of months, before information was actually received in Washington and orders processed and placed. In order to circumvent these difficulties, two methods of purchase have been largely relied upon which, again, will be familiar enough to librarians generallythe direct representative of a department or agency traveling abroad and the blanket order. Neither was satisfactory.

It will be obvious that no single government agency, having large-scale needs for foreign printed materials, could afford enough traveling representatives to attain really world-wide coverage. The Library of Congress, for example, one of the largest single consumers of such materials among the federal agencies, maintained only a few people at a time on collecting missions abroad but never attained the coverage desired. Other agencies could service themselves even less adequately in this respect. Moreover, such representatives, officials of this government, functioned in an inevitably official capacity vis-à-vis other governments. This rendered especially serious such duplications of effort as from time to time occurred in certain - countries, and the Department of State came more and more to the view that the job to be done was essentially a foreign office function and, as such, could not either efficiently or appropriately be accomplished by other agencies than the department itself. In any case, the objectives to be achieved-full coverage, extensive bibliographical information, and efficient and speedy ordering-were not attained in the past through the device of traveling agents.

The technique of the blanket order, placed with a dealer or dealers in a given area, has served the individual agencies' needs no better. Inevitably, the "intake" from any given dealer represented just so much of a substantive field as it profited the dealer to select and forward. Equally inadequate have been the bibliographical aids. Moreover, a great deal of private printing of importance for government research is never represented at all in the usual commercial channels. Finally, even with such information at hand as they could secure through these means, the agencies lost a great deal of material by virtue of time consumed between receipt of information from abroad and the preparation and placing of orders in the field.

\section{Present Methods Inadequate}

The foregoing considerations should serve to show that, of the two principal channels for procurement of foreign publications normally open to this government (purchase and exchange), neither has proved satisfactory judged even by prewar standards. The problem of the future, interpreted in the light of these factors and particularly with reference to the wartime experience, has become that of providing 
such additional channels of procurement as appear necessary, modifying or clarifying the processes within old channels, or both. Chief reliance has been placed upon the latter of these two alternatives in the current planning for future operations.

It has already been pointed out that the foreign service of the United States has, for many years, assisted the government agencies as a whole in procuring foreign printed materials. Under standing instructions from the Department of State, each post has been required to assign to a specific officer the responsibility for complying with requests from Washington. One of the weaknesses of this system has been that in practically no case, even in important publishing centers of the world, could the full time of any officer be afforded for this task. Moreover, few if any of the officers so designated could be presumed to have any technical training in the collection or even assessing of library materials. Nevertheless, over a period of years the foreign service had been able to do a significant enough job in supplementing the agencies' other channels of acquisition to make it obvious that the proper procedure to follow in building up new techniques was first to strengthen the one which had demonstrated its potential.

Accordingly, after a thorough canvass of the problem by its Division of Research and Publication and upon recommendation of that division, the Department of State decided that its new responsibility in the whole acquisitions program was clear and determined to allot to the foreign service (at first through the medium of the Foreign Service Auxiliary) a certain number of full-time, technically-trained officers to be stationed at the principal publishing centers of the world or in those areas from which library materials were most sorely needed, to coordinate the department's field facilities. The task that these officers are expected to perform is, in large measure, reflected in the needs to be served, as judged against the background of the relatively inadequate methods of the past.

\section{Publications Procurement Officers}

In very brief, the activities of the department's publications procurement officers fall into two chief categories-the development of comprehensive bibliographical information services in the field and the acquisition of library materials by exchange, purchase, and gift. This government's needs require that the materials with which the publications officers will be concerned will be varied -books; pamphlets; periodicals; newspapers; federal, provincial, and municipal offcial publications; maps; city plans; and even ephemera such as posters. Their bibliographical reporting is expected to provide current information on basic reference books and treatises, including directories, economic and commercial guides, statistical works, private periodical and other literature published by industrial concerns and scientific societies, as well as information on the status of normal commercial publication outlets.

It is clearly understood that the job to be done will display very different characteristics in different parts of the world. In all cases the intention is to supplement, not to supplant, normal commercial channels long employed by federal agencies. In one location the principal task may be establishing an integrated exchange system; in another, the emphasis may be on coordinating sources of market information; and, in still another, much attention will have to be given to "following through" already initiated exchange and purchase patterns. Too much emphasis cannot, however, be placed upon the fact that (certainly for some time) the department will be able to afford all too few full-time officers for an essentially 
gigantic task. As a consequence, it will not he possible for the publications officers to undertake certain related- functions for which the department would otherwise deem it right and appropriate that they assume responsibility. Substantial assistance to nongovernmental libraries falls in this category. It is hoped, however, that information bulletins and other bibliographical reports which are distributed by the department to the other agencies and which it is believed may be of use to private research institutions, may be made available to such of these institutions as may desire them.

Some of the publications procurement officers to serve under this program are now in the field, the first having been sent out in the spring of 1945. The department has itself learned a great deal about the scope of the over-all problem from the orientation course it established for these men prior to their departure from Washington.

In addition to familiarizing them with the department's side of the program, these officers have been sent (as part of their orientation) to each of the other departments and agencies having acquisitions interests in the countries to which their assignment was being made. Although timeconsuming, this procedure has made it possible for each officer to leave for his post with general and specific wantlists, as well as fairly comprehensive background information on the acquisition problems of each agency. Without this background, sound reporting and servicing from the field would be a virtual impossibility.

\section{Procurement Function}

It has become more and more evident that, although the department's function in this program is strictly that of procurement (as against planning of acquisitions), some sort of integrated acquisitions policy was necessary as between the agencies in
Washington, i.e., that there should emerge a federal acquisitions program. Clearly, the department should assist in procurement. Equally clearly, however, the department can operate effectively only if the acquisition of foreign printed materials is programmed on a government-wide basis. It will not be difficult to imagine that the department's position could easily become untenable if it were called upon to decide between the conflicting needs of agencies. So long as the department views its part of the problem as that of lending assistance to the government, assurance becomes necessary that the problem is also recognized by the other agencies in similarly broad terms. The whole, in this case, is obviously more than the sum of the parts.

The outlines of such a coordinated pattern of federal acquisition of foreign printed materials are now emerging. This is a direct result of the recognition by the several departments and agencies that unrelated and even competitive acquisition has not in the past produced and cannot in the future attain the best results either for the agencies as individual consumers or for the government as a whole.

The department lately requested the $\mathrm{Li}$ brarian of Congress to explore, with the other departments and agencies, a means of providing a continuity of acquisitions policy which could guide it in its procurement activities. In response to this request, the librarian held a series of informal meetings with a group of officials from those agencies most interested in foreign printed materials. After reaching general agreement that coordination and integration of the government's needs were necessary, the librarian was requested to make certain representations to the Secretary of State on behalf of the informal group discussing the problem.

Those representations took the form of a 
request that the secretary give consideration to the establishment of a permanent Interdepartmental Committee on the Acquisition of Library Materials within the framework of the interagency intelligence group which the President had requested him to form. As proposed, the duties and responsibilities of the committee are as follows:

I. To plan a comprehensive program of cooperative acquisitions as between and among the several departments and agencies. The scope of this planning shall include the maintenance of comprehensive research collections of library materials, the rapid interchange and loan of materials, and the distribution of bibliographical information.

2. To originate recommendations to the several departments and agencies concerning the development of their libraries within the framework of over-all federal acquisitions; these recommendations being designed to make available to this government all foreign library materials necessary to the conduct of the public business.

3. To originate recommendations to the Department of State on matters of broad policy connected with the procurement of foreign materials through the foreign service.

4. To review requisitions on the State Department procurement facilities whenever it becomes necessary to determine whether said requisitions are consistent with the committee's comprehensive acquisitions program.

It should, perhaps, be pointed out that the basic philosophy of the committee negates the principle of agency representation. For members of the committee to conceive of themselves, or for their agencies to conceive of them, solely as representatives of the interests of the governmental bodies to which they are attached, would render most difficult the primary task of attaining broad consideration of federal acquisition policy. The situation demands, instead, the continuous deliberation of individuals whose responsibility and chief interest lies in substantive fields of knowledge not necessarily encompassed by the rigid framework of governmental administrative structures. It is hoped that primary allegiance to the problem may be. attained through a technique which assumes a committee of "experts" rather than a committee of "representatives." Indeed, specific provision has been made within the internal structure of the committee to deal with its problems on a substantive rather than on an agency basis.

\section{Executive Subcommittee}

Although membership is open to all agencies having responsibilities in the field of foreign acquisition, an operating executive subcommittee, selected by the whole committee, is also provided for. Of first importance is the principle that the problems of acquisition in specific fields of knowledge are considered by subcommittees pro tem composed of individuals whose agencies deal most largely with the particular fields in question, i.e., medicine, law, physical sciences, aeronautics, and so on.

From the point of view of government officials vitally concerned with acquisition of foreign materials, the techniques outlined herein give considerable promise. It is hoped that the result will be the meeting of a total rather than a partial problem by those cooperative means by which alone the real issues can be resolved.

\section{Service to Private Libraries}

The principal private research libraries of the country have not infrequently had occasion to solicit the aid of the department in the solution of certain of their problems of foreign procurement. Wherever appropriate and possible, the department has lent such assistance as it could. Nevertheless, it must be said that the department has never been in a position to match the sympathetic consideration with which it viewed these problems with positive action 
on a sufficient scale to satisfy private libraries.

It must not be supposed that the department, through the medium of its publications officer program or by other means, can promise at this time to do for private research institutions many of the things that it might be highly desirable for it to do. On the other hand, it is prepared to redefine somewhat more broadly the scope of its procurement activities. This redefinition, already stated in part, can benefit nongovernmental institutions to a considerable degree.

Responsible officials of private libraries have long recognized that, as a matter of principle, it was inappropriate for the Department of State to employ its resources directly in behalf of nongovernmental institutions. Although this principle will remain valid in general, the department is now prepared to endorse certain exceptions to it.

The exigencies of the recent war and the rigid control of the marketing of published materials still prevailing in certain countries, have combined to make it extremely difficult for private institutions to acquire library materials of any kind in certain areas. After reviewing this problem with representatives of a number of the research libraries, the department has adopted the view that its (i.e., governmental) channels of acquisition could be made available to nongovernmental institutions under certain circumstances.

Wherever normal commercial channels have become inoperative and it can be demonstrated that it is in the national interest that material be procured from areas thus restricted, even though they are in part intended for private research collections, the Department of State is prepared to employ the means at its disposal for their procurement. This policy presupposes (I) that the holdings in certain fields of knowledge are of importance to this government whether or not they are governmental holdings per se, (2) that those responsible for such private holdings will, when requesting government assistance, present to the department evidence that they have evolved and will adhere to a plan of cooperative acquisition which will adequately correlate total nationwide collections in the various fields of knowledge, and (3) that the department reserves the right to determine when and for how long conditions obtain which render it possible for government channels to be used in this manner.

\section{L.C.'s Relationship to Program}

The Library of Congress has agreed to act in an administrative and liaison capacity with the department and the nongovernmental institutions in order to provide a suitable supplementary mechanism in this regard. Private research institutions having specialized collections of national importance, which find themselves unable to augment these collections through normal commercial dealings, may make known their needs to the Librarian of Congress. If the library and the department agree on the justification for the request, in terms of the policies outlined above, the librarian is prepared to order titles in multiple copy through the Department of State, he (the librarian) being reimbursed by them for such copies as he distributes to the private libraries.

\section{Summary}

In summary, the department is presently embarking upon an expanded program of assistance to this government in the field of procurement of foreign library materials. It is doing this because it recognizes, together with the other agencies of this (Continued on page 108) 
ment by the middle of December 1945 .

The weekly abstract bulletin will be made available to depository libraries. Others may subscribe to it through the Superintendent of Documents.

In its present state this material is comparable in size to one of our great research collections, but it is scattered all over the country and over half the world in boxes, bundles, files, caves, and possibly even in the inevitable salt mines. Most of it is available in manuscript form only, or in a single, poor, microfilm copy. There is no catalog of this material nor has it been organized, so that no one really knows what is available or where it may be.

Obviously, a large portion of our own classified or enemy reports is of little value for practical industrial application in the immediate future. A large portion of it may be worthless. The publication board's job is that of acquiring material as rapidly as possible and organizing it so that final selection may be made by those who will apply this knowledge to the industrial and economic benefit of the country.

One of the important tools which will develop from the operations of the library unit of the board will be a master subject card index which will eventually provide a guide to the knowledge contained in this great mass of scientific and technical literature.

The responsibility of the librarians employed by the board to organize this material is a heavy one, but still greater is the responsibility of the librarians of research, industrial, and other special libraries who will, in the final analysis, be responsible for making the truly important and immediately applicable information available to their own organizations.

\section{The Department of State and Acquisition of Foreign Materials}

\section{(Continued from page 104)}

government, the transcendent importance of such materials in day-to-day federal operations. Moreover, the department has recognized the principle that certain private collections of such material are of national importance, although they are not and should not be duplicated in Washington, and has consequently held that department assistance may be given these collections in their procurement problems under certain circumstances.

It is hoped and expected that the techniques embraced by this expanded program will greatly benefit those responsible for the conduct of the public business. It is also hoped that material assistance can, where it is justified, be given to private institutions. The private institutions must regard seriously, however, their responsibility so to correlate their several acquisitions needs that, when assistance is requested in a given area, an integrated program can be presented to the department by the libraries. The department hopes that such coordination within the government can be achieved through the efforts of the interdepartmental committee. It must have a similar background against which to work when it undertakes to aid nongovernmental research institutions. 